\title{
Review \\ Peri-Implantitis: A Clinical Update on Prevalence and Surgical Treatment Outcomes
}

\author{
Andrea Roccuzzo ${ }^{1,2,+} \oplus$, Alexandra Stähli ${ }^{1,+}$, Alberto Monje ${ }^{3}\left(\mathbb{D}\right.$, Anton Sculean $\left.{ }^{1}{ }^{(}\right)$and Giovanni E. Salvi ${ }^{1, *}$ \\ 1 Department of Periodontology, School of Dental Medicine, University of Bern, Freiburgstrasse 7, \\ 3010 Bern, Switzerland; andrea.roccuzzo@zmk.unibe.ch (A.R.); alexandra.stähli@zmk.unibe.ch (A.S.); \\ anton.sculean@zmk.unibe.ch (A.S.) \\ 2 Department of Oral and Maxillofacial Surgery, Copenhagen University Hospital (Rigshospitalet), \\ 2100 Copenhagen, Denmark \\ 3 Departamento de Periodontología, Universitat Internacional de Catalunya, 08195 Barcelona, Spain; \\ amonjec@umich.edu \\ * Correspondence: giovanni.salvi@zmk.unibe.ch; Tel.: +41-(0)31-632-25-89; Fax: +41-(0)31-632-49-15 \\ + The authors share the first position.
}

Citation: Roccuzzo, A.; Stähli, A.; Monje, A.; Sculean, A.; Salvi, G.E. Peri-Implantitis: A Clinical Update on Prevalence and Surgical Treatment Outcomes. J. Clin. Med. 2021, 10 , 1107. https://doi.org/10.3390/ jcm10051107

Academic Editors: Hugo De Bruyn and Gianrico Spagnuolo

Received: 8 February 2021

Accepted: 23 February 2021

Published: 6 March 2021

Publisher's Note: MDPI stays neutral with regard to jurisdictional claims in published maps and institutional affiliations.

Copyright: (c) 2021 by the authors. Licensee MDPI, Basel, Switzerland. This article is an open access article distributed under the terms and conditions of the Creative Commons Attribution (CC BY) license (https:// creativecommons.org/licenses/by/ $4.0 /)$.

\begin{abstract}
Dental implants may be considered a reliable routine procedure in clinical practice for the replacement of missing teeth. Results from long-term studies indicate that implant-supported dental prostheses constitute a predictable treatment method for the management of fully and partially edentulous patients. Implants and their restorations, however, are not free from biological complications. In fact, peri-implantitis, defined as progressive bone loss associated to clinical inflammation, is not a rare finding nowadays. This constitutes a concern for clinicians and patients given the negative impact on the quality of life and the sequelae originated by peri-implantitis lesions. The purpose of this narrative review is to report on the prevalence of peri-implantitis and to overview the indications, contraindications, complexity, predictability and effectiveness of the different surgical therapeutic modalities to manage this disorder.
\end{abstract}

Keywords: peri-implantitis; biological complications; bone regeneration; dental implants

\section{Introduction}

At the 2017 World Workshop on the Classification of Periodontal and Peri-implant Diseases and Conditions, new disease and case definitions were presented for peri-implant health, peri-implant mucositis and peri-implantitis [1].

Epidemiologic reports on peri-implant diseases across the globe demonstrated a wide range according to the population screened and the case definition adopted. Other factors, such as compliance with supportive therapy and characteristics of patient samples and implant recipient sites may influence heterogeneity in reporting and make comparisons among studies challenging. For example, outcomes of a publication on the effectiveness of implant therapy in a Swedish population sample indicated that significantly higher odds ratios for moderate/severe peri-implantitis were found for patients diagnosed with periodontitis (OR 4.08) compared with periodontally healthy patients [2].

Without discriminating between implants placed in native vs. augmented bone, the prevalence of peri-implant diseases was reported from longitudinal [3] and from cross-sectional studies, respectively [4-10]. The outcomes of a systematic review with meta-analysis reported a weighted mean prevalence of peri-implant mucositis of $43 \%$ (range: 19-65\%) and of peri-implantitis of 22\% (range: 1-47\%), respectively [3].

Alveolar ridge augmentation is a frequent procedure in implant dentistry. Outcomes of clinical studies on the long-term survival rates of implants placed in augmented vs. pristine bone is still controversial. While some studies indicated comparable outcomes in terms of implant survival rates and marginal bone loss [11-15], other studies reported inferior results for implants placed in augmented sites [5,16-18]. 
Considering the difficulties in performing clinical trials with appropriate design and patient selection, the question of potential differences between the progression of periimplantitis in augmented vs. native sites was addressed in a pre-clinical in vivo study using the experimental peri-implantitis model in Labrador dogs. The outcomes of that study indicated that the size and vertical dimension of the peri-implantitis lesion were larger at augmented sites compared with native sites. Moreover, it was demonstrated that implants with non-modified (i.e., turned) surfaces exhibited smaller amounts of bone loss and smaller dimensions of peri-implantitis lesions compared with implants with modified (i.e., micro-rough) surfaces [19].

It was the aim of the present narrative review to evaluate existing evidence on the prevalence and treatment outcomes of peri-implantitis focusing on surgical treatment protocols.

\section{Prevalence of Peri-Implantitis}

Although over the last decades dental implants proved to be highly effective in replacing teeth with survival rates exceeding $95 \%$ over 10 years [20], biological complications compromise implant longevity. Accordingly, there is an increase in the treatment needs to arrest such disorders. Before comparing biological complications and outcomes of implants placed in native vs. augmented bone, the prevalence of peri-implantitis and the caveats of its interpretation are presented below.

Firstly, described in 1993, at the First European Workshop on Periodontology, periimplant diseases have been widely investigated. Outcomes from experimental mucositis and peri-implantitis studies highlighted the cause-and-effect relationship between bacterial biofilms accumulation and inflammatory tissue alterations [21-23] and a plethora of studies assessed clinical and histopathological features, disease definitions, prevalence, risk indicators and treatment modalities. Over time, numerous disease definitions have been proposed and different clinical parameters have been defined. Consequently, a wide range of prevalence have been reported and their results published in a systematic review with meta-analysis [3]. Moreover, in a case series of 86 patients with a very long follow-up (i.e., range of 21-26 years), peri-implant mucositis and peri-implantitis prevalence amounted to $54.7 \%$ and $22.1 \%$, respectively [24].

It should be highlighted that adopting different cut-off thresholds of marginal bone loss, a wide range of prevalence of peri-implantitis was reported [3]. Defining a threshold of marginal bone loss $>5 \mathrm{~mm}$ yielded a prevalence of peri-implantitis of $1 \%$ [25] whereas a threshold of $0.4 \mathrm{~mm}$ marginal bone loss increased the prevalence of peri-implantitis to $47 \%$ [26].

In addition, it has to be differentiated between cases with baseline radiographs in which 1-1.5 mm of marginal bone loss has been proposed to define peri-implantitis and cases without baseline radiographs in which $2 \mathrm{~mm}$ of marginal bone loss after the initial remodeling phase account for the definition of peri-implantitis [27].

When peri-implantitis prevalence is reported, the level of reporting (i.e., implant vs. patient) must also be taken into consideration. For example, the prevalence of periimplantitis was reported to be $1 \%$ at patient- and $0.4 \%$ at implant-level, respectively [25].

When comparing the prevalence of peri-implant diseases and failure rates of implants placed in native versus augmented bone, studies are scarce although tissue deficiencies resulting from bone remodeling, trauma or infections do often occur. For example, following atraumatic tooth extraction buccal alveolar fracture was observed in $9 \%$, bony dehiscence in $28 \%$ and complete buccal plate loss in $4 \%$, respectively [28]. Consequently, augmentation procedures simultaneous or delayed to implant placement are commonly performed. Now, the question falls on whether or not differences in the prevalence of peri-implant diseases at implants placed in augmented vs. native sites exist. A systematic review including 8 studies addressed this issue [29]. After a follow-up of at least 10 years, the patient-based weighted mean prevalence of peri-implant mucositis amounted to $22.4 \%$ (95\% CI: 6-38\%) in native and to $19.6 \%$ (95\% CI: 0-40\%) in augmented sites, respectively. Although no sta- 
tistically significant differences were observed with respect to the patient-based prevalence of peri-implantitis of implants placed in native (10.3\%; $95 \%$ CI: 4-17\%) vs. augmented sites $(17.8 \% ; 95 \%$ CI: 0-37\%), patients treated with implants in augmented sites displayed higher variability in terms of peri-implantitis compared to patients with implants in native sites. Patient-based implant failures were observed in $2.5 \%$ of native and in $3.6 \%$ of augmented sites, respectively. Again, the studies included in that systematic review displayed a wide range of definitions of peri-implantitis [29]. For example, Roccuzzo and co-workers defined marginal bone loss of $\geq 2 \mathrm{~mm}$ as peri-implantitis [30] while Tenenbaum and co-workers set the threshold for bone loss at $\geq 4.5 \mathrm{~mm}$ [31].

Taken together, studies on the prevalence of peri-implantitis yield a high heterogeneity in terms of case definitions, patient sampling and clinical scenarios (Figures 1-3).

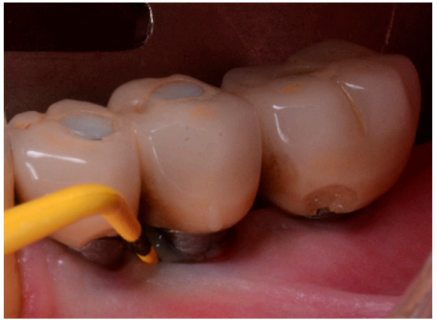

(a)

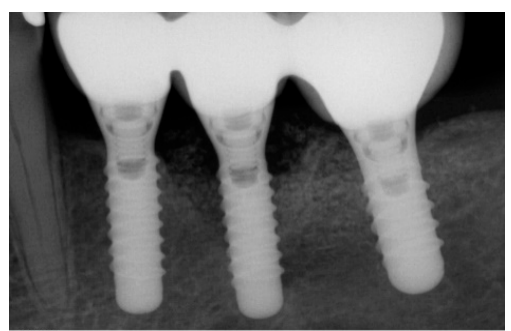

(b)

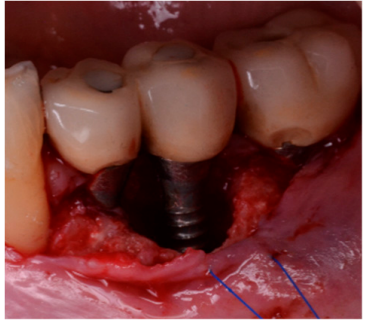

(c)

Figure 1. (a) Mandibular left premolar implant showing an increase in probing pocket depth as compared with previous records, bleeding and pus exhibiting shortly after probing. Note, the shallow vestibulum at the buccal aspect of the infected implant; (b) Radiographic image revealing significant bone loss. Note, the remaining particles of an anorganic bovine bone previously used for grafting; (c) Intra-operative appearance of the peri-implant infra-osseous defect after debridement. Note, the remaining particles of an anorganic bovine bone previously used for grafting simultaneously at implant placement stage.

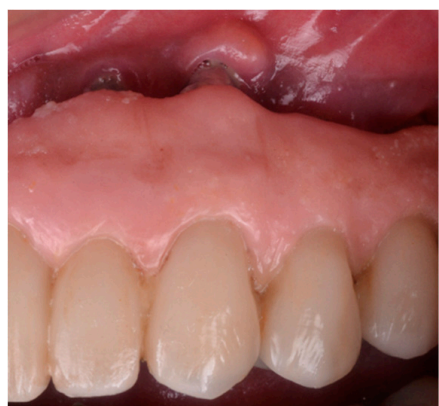

(a)

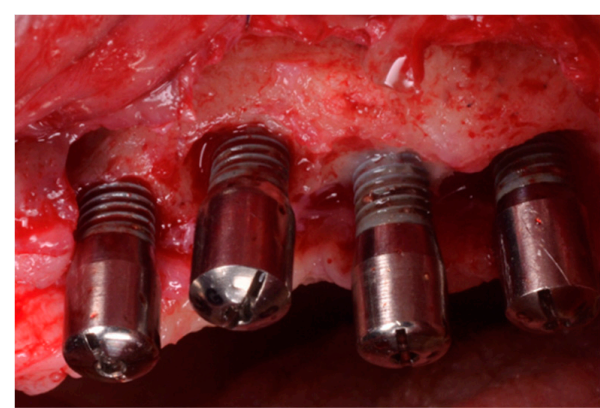

(b)

Figure 2. (a) Clinical appearance of implants placed in bone augmented with anorganic bovine bone and autogenous bone 5 years after placement in a smoker patient. Note, the poor plaque control and the inadequate prosthesis design that precluded adequate self-performed oral hygiene measures; (b) Intra-operative appearance of the peri-implant defects after debridement. Note, the predominant horizontal pattern of bone resorption.

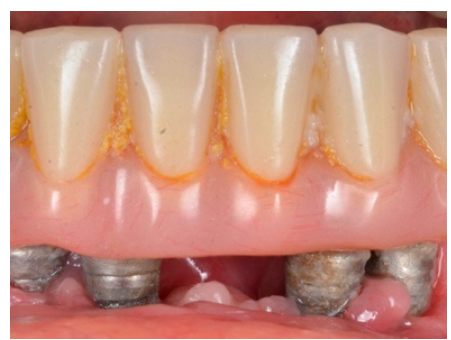

(a)

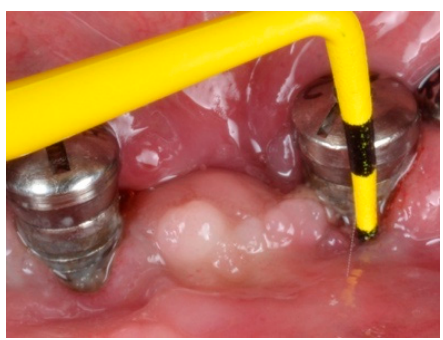

(b)

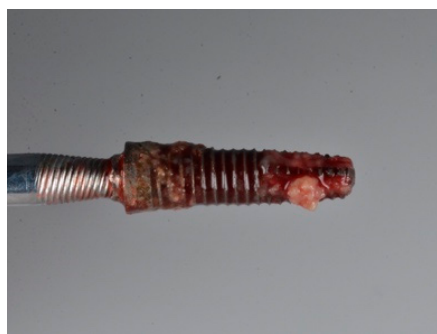

(c)

Figure 3. (a) Clinical appearance at several implant-supported fixed prosthesis involved affected of advanced periimplantitis; (b) clinical probing indicates advanced attachment loss; (c) implant removal is suggested in advanced forms of peri-implantitis. 


\section{Surgical Treatment Approaches and Outcomes of Peri-Implantitis Therapy}

Despite attempts to successfully treat peri-implantitis with non-surgical approaches (i.e., mechanical debridement) often in association with adjuncts (local and systemic antimicrobials, lasers, photodynamic therapy, etc.), it has been clinicians' experience that the overall benefit in terms of changes in clinical parameters such as pocket probing depth (PPD) and bleeding on probing (BoP) is limited [32]. Indeed, due to the frequent presence of deep peri-implant pockets, different macro and micro implant surface characteristics, and difficult access for biofilm removal, access to implant surfaces for decontamination may be extremely challenging. Therefore, the use of nonsurgical protocols should be performed with the aim of preparing healthier peri-implant soft tissue conditions prior to adjunctive surgical therapy $[32,33]$.

Following a treatment sequence taken from the periodontal surgical literature, the surgical management of peri-implantitis initiates with the elevation of a full-thickness flap to get access to the contaminated implant surface. Consequently, after peri-implant soft-tissue defect degranulation, an accurate surface decontamination should be performed. Over the years, several hand (i.e., titanium and teflon curettes) and power-driven instruments have been developed (i.e., glycine powder, ultrasonics, titanium and chitosan brushes) with the aim to optimize biofilm removal without altering the implant surface. Nonetheless, at the present time, none of the investigated tools have been proven to be superior in terms of peri-implant surface decontamination [34]. Therefore, it is suggested to combine a mechanical and chemical decontamination process prior to the assessment of the peri-implant bone defect configuration.

Following implant surface decontamination, four main surgical modalities have been described in the literature for treating peri-implant bony defects.

\subsection{Open Flap Debridement without Resective Procedures}

Open flap debridement (OFD) includes elevation of a mucoperiosteal flap with additional removal of granulation tissue in order to gain access to the contaminated implant surface. Following removal of the inflammatory tissue, the implant surface is decontaminated by means of mechanical, chemical, and/or additional (e.g., photodynamic therapy and laser) methods followed by mucoperiosteal flap repositioning and closure. Studies evaluating the outcomes of open flap debridement without resection procedures have reported high survival rates and moderate composite success rates (e.g., PPD $\leq 5 \mathrm{~mm}$, absence of bleeding/suppuration on probing, and absence of progressive bone loss) up to 5 years following treatment [35,36]. More specifically, the results obtained by Heitz-Mayfield and co-workers after OFD with adjunctive delivery of systemic antimicrobials (i.e., amoxicillin $500 \mathrm{mg}$ and metronidazole $400 \mathrm{mg}, 3 x /$ day for 7 days) reported complete disease resolution of around $19(53 \%)$ implants in $15(63 \%)$ patients. These results underlined the challenges for maintaining mid- to long-term, the positive short-term results.

\subsection{Open Flap Debridement with Resective Procedures}

Outcomes of a five-year study evaluating a resection approach with bone recontouring and adjunctive delivery of systemic antimicrobials indicated that $54 \%$ of implants yielded a successful outcome defined as disease resolution [37]. Indeed, 57 implants (44\%) displayed disease recurrence/progression and among these, 27 had to be removed. Interestingly, a statistically significant correlation between residual PPD $\geq 6 \mathrm{~mm}$ (OR 7.4, 95\% CI 2.8-19.3) and reduced marginal bone levels (OR 1.4, 95\% CI 1.1-1.7) at the one-year follow-up and recurrence/progression of peri-implantitis was found. Moreover, implants with a modified surface were found to be at higher risk for disease progression as compared with implants with a non-modified surface (OR 5.1, 95\% CI 1.6-16.5).

Comparable results were reported by Berglundh and co-workers in a long-term retrospective cohort study with an observation period of up to 11 years (2-11 years) [38]. All the 95 implants placed in 50 patients underwent OFD followed by osseous recontouring to obtain pocket elimination. The clinical and radiographic results revealed positive outcomes 
in terms of PPD and BoP changes and confirmed how implant surface characteristics (i.e., turned vs. modified surfaces) have an impact on the final outcomes [38]. The impact of the implant surface characteristics on implant survival and success rates after surgical treatment of peri-implantitis has also been assessed by other authors [39,40]. Indeed, at the seven- and 10-year follow-up adopting a reconstructive surgical protocol using a deproteinized bovine bone mineral (DBBM) with $10 \%$ collagen, patients rehabilitated with sand-blasted and acid-etched (SLA) implants presented an implant survival rate of $80 \%$, while patients who received implants with a titanium plasma sprayed (TPS) surface presented an overall survival rate of $55 \%$.These results indicated that implants with a moderately rough surface (i.e., SLA) performed better as compared with those with a higher surface roughness (i.e., TPS).

Comparable results were recently reported in a long-term retrospective study with a follow-up of 11 years [41]. All the implants which had to be removed before the final examination had a modified surface $(n=8,14 \%)$, while implants with a turned surface did not experience any loss [41].

Implantoplasty, which is defined as removal of the supracrestal implant threads and exposed surface, can also be performed as part of a resection approach. The rationale for performing an implantoplasty procedure is to alter the implant surface topography in order to facilitate biofilm removal by the patient. Controversial evidence, however, exists in terms of the advantages of implantoplasty procedures as compared with other methods of decontamination in the surgical management of peri-implantitis (Figure 4).

In the surgical management of peri-implantitis, the efficacy of implantoplasty was investigated and compared with a bone resection approach alone in terms of marginal bone level (MBL) changes over a follow-up period of 3 years [42]. In that study, 10 patients were treated with open flap debridement (OFD) in combination with implantoplasty, while nine patients underwent a bone recontouring procedure alone. At the three-year evaluation, peri-implant MBL changes following implantoplasty were significantly smaller as compared with those observed in the control group.

Results of a case series study indicated that a combined bone resection procedure with implantoplasty resulted in marginal bone level stability and disease resolution in $89 \%$ of the implants after a mean follow-up of 3.4 years [43].

Recently, the efficacy of implantoplasty was evaluated and compared with that obtained using an air-polishing device with glycine powder in the surgical management of peri-implantitis in a six-month randomized clinical trial [44]. Following flap elevation and removal of granulation tissue, implant surfaces were either decontaminated with implantoplasty $(n=22)$ or with the air-polishing device $(n=20)$ and no grafting materials or barrier membranes were applied within the defects. At the three- and six-month clinical examinations, comparable clinical results in terms of changes in PPD and BoP were observed between the two groups indicating that implantoplasty was as effective as glycine air polishing in the surgical management of peri-implantitis [44].

Unfortunately, there is lack of clinical evidence describing the consequences of implantoplasty procedures such as implant fracture and presence of titanium particles in the peri-implant soft tissues [45]. Therefore, the question whether a procedure such as implantoplasty should be recommended or not to decontaminate implant surfaces remains controversial. 


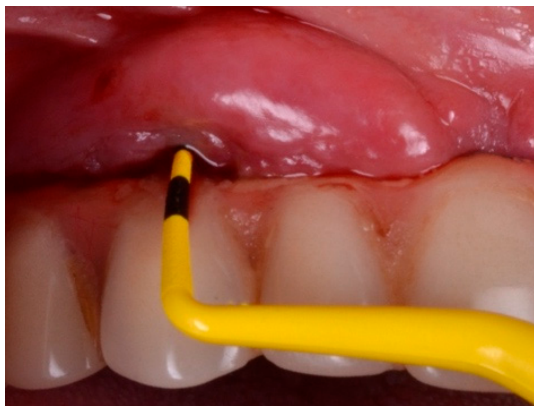

(a)

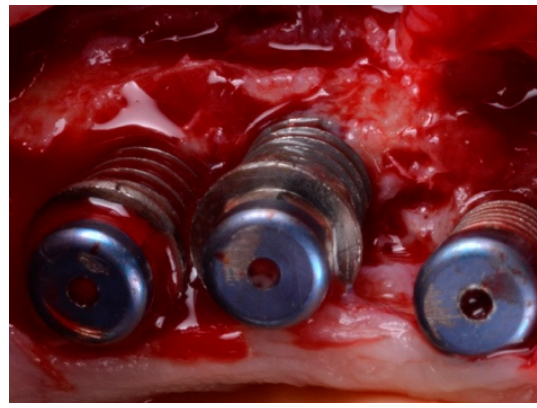

(c)

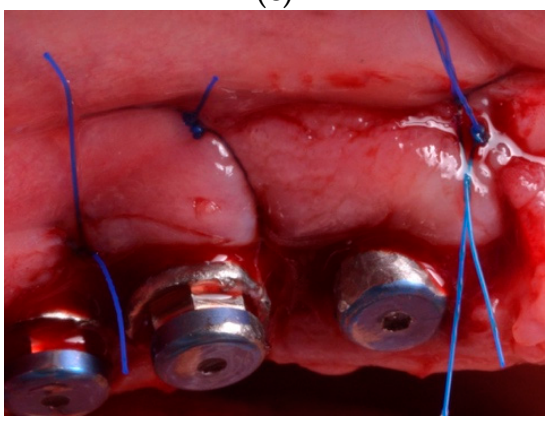

(e)

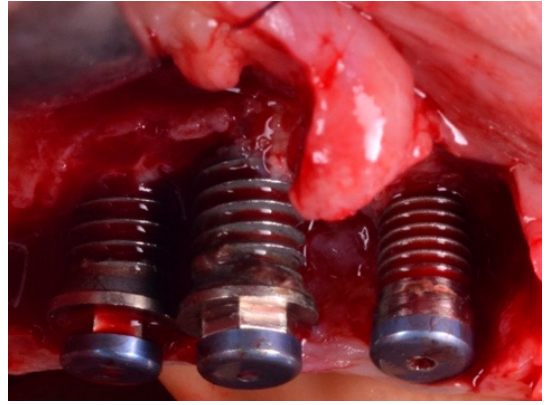

(b)

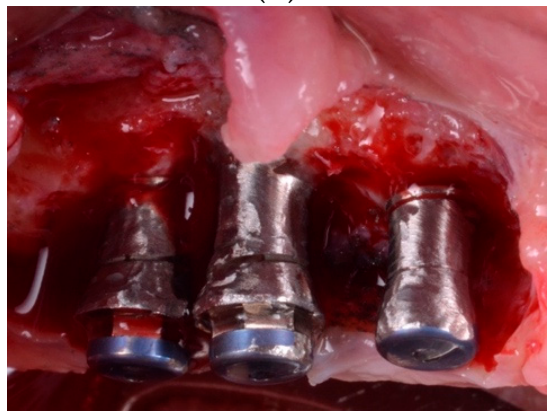

(d)

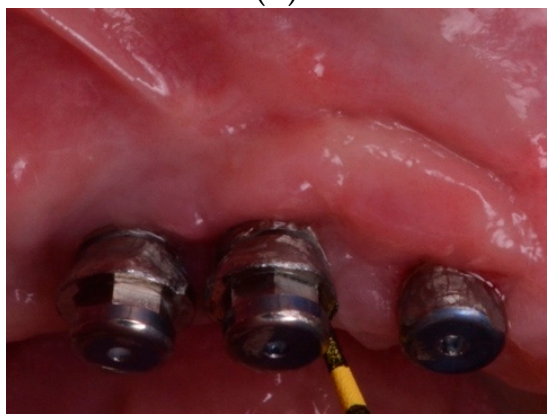

(f)

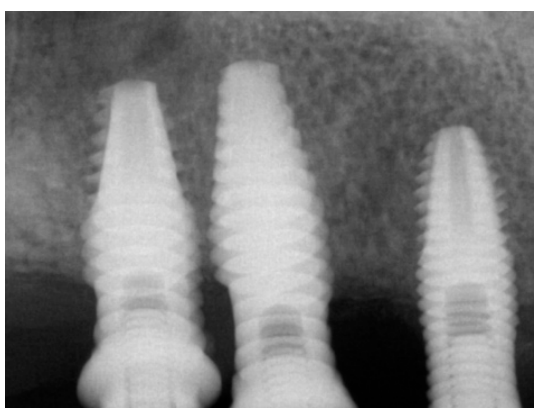

(g)

Figure 4. (a) Clinical presentation of peri-implantitis; (b) Access flap reveals moderate bone loss $(<50 \%)$ (frontal view). Note the supra-crestal defect morphology; (c) Occlusal view of moderate bone loss; (d) Implantoplasty was performed as adjunct to the surgical resective therapy of peri-implantitis (frontal view); (e) Occlusal view of the implantoplasty and bone topography after osteoplasty to reach a flat bone architecture; (f) clinical resolution of peri-implantitis at 6-month follow-up; (g) bone stability is noted upon radiographic assessment.

\subsection{Reconstructive Procedures}

Following preclinical [46] and clinical [47] evidence of the possibility to obtain reosseointegration around dental implants affected by peri-implantitis, several studies proposed different reconstructive protocols using autogenous bone and/or various bone substitutes (Figure 5) and barrier membranes to treat peri-implantitis defects [48-56]. 


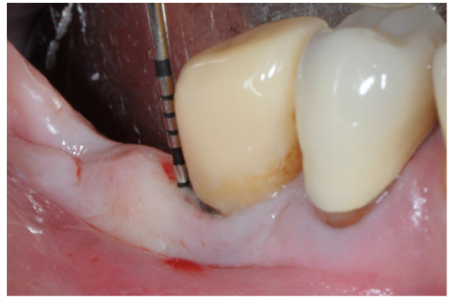

(a)

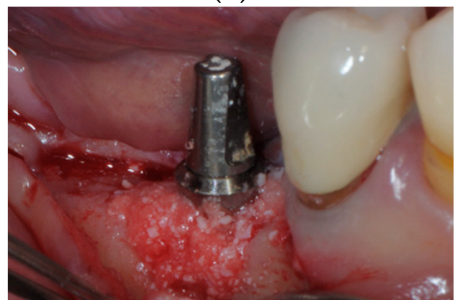

(c)

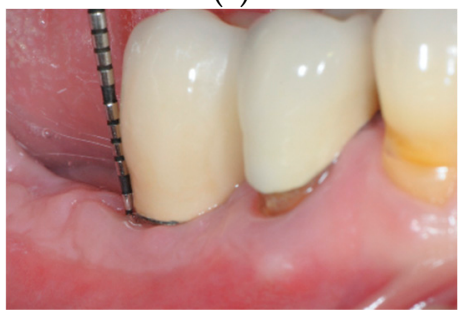

(e)

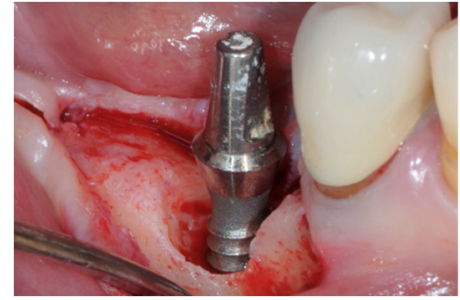

(b)

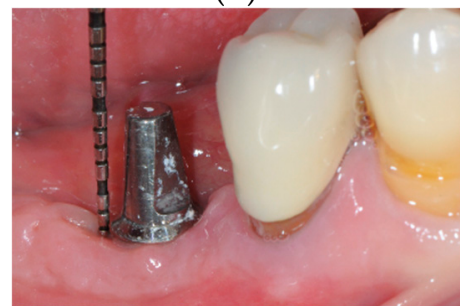

(d)

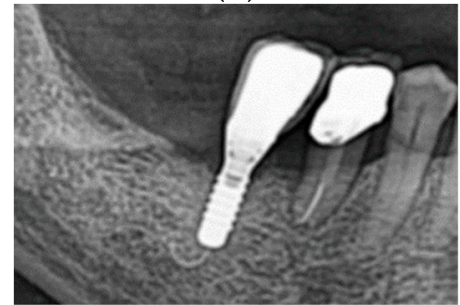

(f)

Figure 5. (a) Mandibular right premolar implant installed in pristine bone showing increased probing pocket depth as compared with previous records, bleeding and pus exhibiting shortly after probing; (b) Intra-operative appearance of the peri-implant infra-osseous defect after debridement; (c) Anorganic bovine bone mineral with $10 \%$ collagen is applied in the infra-osseous component; (d) Six-month follow-up after non-submerged healing, no signs of inflammation and peri-implant probing depth was noted to be consistent with health; (e) One-year follow-up after delivery of the final restoration. Note, peri-implant stability; (f) Radiographic image, at 1-year follow-up, reveals substantial bone fill.

A randomized controlled trial (RCT) evaluated the adjunctive use of a demineralized bovine bone substitute and failed to report additional radiographic hard tissue fill as compared with open flap debridement alone [56]. However, a composite assessment of clinical and radiographic parameters identified that surgical debridement with adjunctive use of a bone substitute was more predictable as compared with open flap debridement alone in contained defects with 3-4 bony walls [56].

Results of a recent systematic review [57] reported limited evidence available from three RCTs [58-60] with a total of 116 implants evaluating the effects of a reconstructive approach as compared with open flap debridement alone and indicated a benefit in radiographic marginal hard tissue level changes when using a reconstructive approach. However, the reconstructive protocols described in the three RCTs included in the systematic review (i.e., adjunctive use of porous titanium granules and enamel matrix derivative) do not represent commonly used surgical procedures to treat peri-implantitis defects. In addition, the porous titanium granules are no longer commercially available.

In terms of disease resolution, no significant differences in clinical parameters (i.e., reduction in PPD and BoP scores) were observed as compared with a reconstructive approach with open flap debridement alone [57].

\subsection{Combined Resective and Reconstructive Procedures}

The use of a combined resection (i.e., implantoplasty of the supracrestal portion of the implant) and reconstructive (i.e., filling of the infrabony component of the defect) approach 
has been described adopting transmucosal [61,62] and submerged [63] healing protocols, respectively.

Outcomes of a combined surgical protocol including implantoplasty of the suprabony component and application of a DBBM grafting material with a collagen membrane in the intrabony portion of the peri-implant defect were reported in a 12-month case series study. Statistically significant clinical improvements in terms of PPD and Clinical Attachment Level (CAL) changes and an increase in mucosal recession were observed after 1 year [61].

Changes in clinical parameters of implants treated with a combined resection (i.e., implantoplasty of the supracrestal implant portion) and reconstructive approach were reported in a study including 15 patients with a follow-up of 7 years [62]. Following surface decontamination with either an Er:YAG laser or plastic curettes with cotton pellets and saline solution, the intrabony components of the peri-implant defects were treated by means of a grafting material and a collagen membrane. Comparable clinical conditions in terms of BoP reduction and CAL gain were reported in both groups irrespective of the method of surface decontamination [62].

The clinical and radiographic results in the reconstructive management of two- or three-wall peri-implantitis defects were reported in a case series study [63]. Fifteen patients diagnosed with peri-implantitis underwent a combined resection (i.e., implantoplasty of the supracrestal implant portion) and reconstructive (i.e., filling of the intraosseous compartment) approach followed by a submerged healing without restorations in situ for 8-10 weeks. At the 6- and 12-month follow-up examinations, statistically significant reductions in PPD and BoP, as well as radiographic hard tissue fill, were recorded. Owing to the marked mean post-surgical mucosal recession of $2.5 \mathrm{~mm}$, a treatment which has been proven to be of limited efficacy [64], this combined surgical approach may be applied to posterior implant areas of limited esthetic priority [63].

\subsection{Soft Tissue Conditioning with Resective Procedures}

The significance of keratinized mucosa on tissue health has been demonstrated $[65,66]$. On the contrary, the influence of keratinized mucosa on the therapeutic outcomes of peri-implantitis remains unclear [67].

Recently, a protocol has been described to manage supra-crestal and/or dehiscencetype peri-implantitis bone defects associated with lack of keratinized mucosa (Figure 6). Four steps define the success of this: (1) partial-thickness flap apically positioned, (2) bone recontouring to achieve a flat architecture, (3) implantoplasty for the exposed implant surface and, (4) free epithelial graft stabilized on the vascular recipient bed. A prospective case series [68] demonstrated complete disease resolution in $78.6 \%$ of the patients and $87.1 \%$ of the peri-implantitis implants. Interestingly, unsuccessful cases were associated with less gain of keratinized mucosa, deep pocket probing depths, bleeding on probing, and less satisfaction during brushing at 12 months.

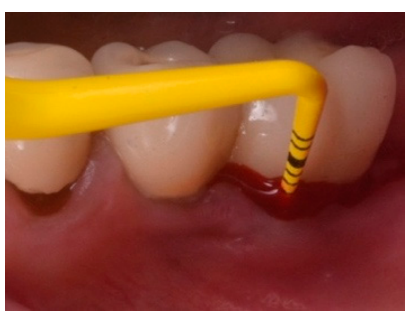

(a)

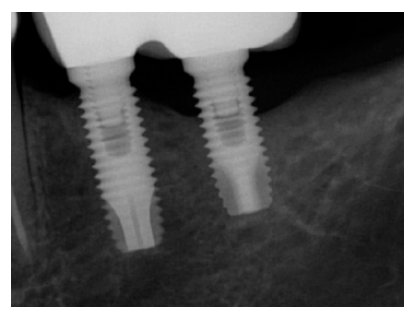

(b)

Figure 6. Cont. 


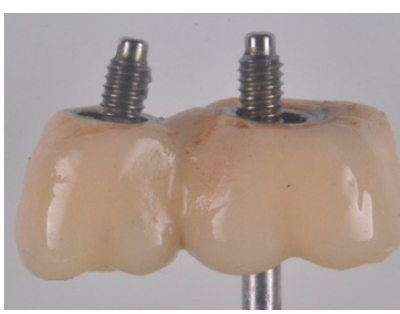

(c)

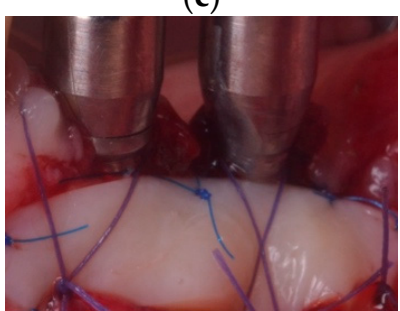

(e)

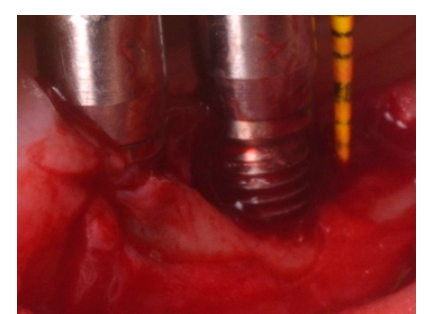

(d)

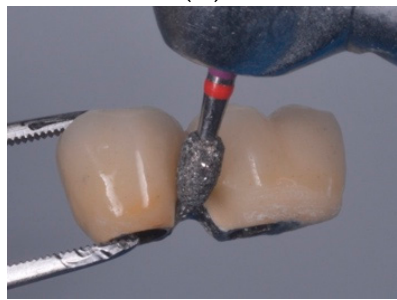

$(\mathbf{f})$

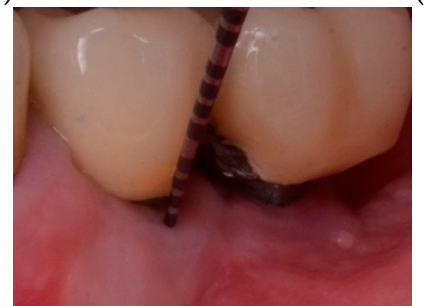

(g)

Figure 6. (a) Clinical presentation of peri-implantitis; (b) Radiographic image compatible showing moderate $(<50 \%)$ bone loss; (c) Inadequate prosthesis emergence profile; (d) Partial-thickness apical position flap; (e) Soft tissue conditioning by means of free epithelial graft; (f) Prosthesis contour modification to facilitate proximal access during self-performed oral hygiene; (g) Clinical resolution of peri-implantitis associated with a gain of keratinized mucosa.

\section{Conclusions}

The following conclusions can be drawn from the present review:

- Clinical and radiographic features define peri-implantitis

- Prevalence of peri-implantitis relies upon case definition.

- Patient's characteristics such as history of periodontitis, tobacco consumption, compliance with supportive therapy as well as implant topographic characteristics differed considerably among studies, limiting thus, the interpretation and generalizability of the obtained outcomes.

- $\quad$ Based on the limited effectiveness of non-surgical procedures, a wide range of surgical protocols and biomaterials used for the management of peri-implantitis lesions have been described in the literature with scarce long-term evidence.

Author Contributions: Conceptualization, A.R., A.S. (Alexandra Stähli) and G.E.S.; methodology, A.R., A.S. (Alexandra Stähli) and G.E.S.; writing-review and editing, A.R., A.M., A.S. (Alexandra Stähli) and G.E.S.; supervision, A.S. (Anton Sculean), A.M., and G.E.S. All authors have read and agreed to the published version of the manuscript.

Funding: This research received no external funding.

Acknowledgments: A.R. is the recipient of a three-year scholarship from the Clinical Research Foundation (CFR) for the Promotion of Oral Health, Brienz, Switzerland.

Conflicts of Interest: The authors declare no conflict of interest. 


\section{References}

1. Berglundh, T.; Armitage, G.; Araujo, M.G.; Gustavo, A.-O.; Juan, B.; Paulo, M.C.; Stephen, C.; David, C.; Jan, D.; Elena, F.; et al. Peri-implant diseases and conditions: Consensus report of workgroup 4 of the 2017 World Workshop on the Classification of Periodontal and Peri-Implant Diseases and Conditions. J. Periodontol. 2018, 89, S313-S318. [CrossRef] [PubMed]

2. Derks, J.; Schaller, D.; Håkansson, J.; Wennström, J.L.; Tomasi, C.; Berglundh, T. Effectiveness of implant therapy analyzed in a Swedish population: Prevalence of peri-implantitis. J. Dent. Res. 2016, 95, 43-49. [CrossRef]

3. Derks, J.; Tomasi, C. Peri-implant health and disease. A systematic review of current epidemiology. J. Clin. Periodontol. 2015, 42, S158-S171. [CrossRef] [PubMed]

4. Aguirre-Zorzano, L.A.; Estefania-Fresco, R.; Telletxea, O.; Bravo, M. Prevalence of peri-implant inflammatory disease in patients with a history of periodontal disease who receive supportive periodontal therapy. Clin. Oral Implant Res. 2015, 26, 1338-1344. [CrossRef]

5. Daubert, D.M.; Weinstein, B.F.; Bordin, S.; Leroux, B.G.; Flemming, T.F. Prevalence and predictive factors for peri-implant disease and implant failure: A cross-sectional analysis. J. Periodontol. 2015, 86, 337-347. [CrossRef] [PubMed]

6. Konstantinidis, I.K.; Kotsakis, G.A.; Gerdes, S.; Walter, M.H. Cross-sectional study on the prevalence and risk indicators of peri-implant diseases. Eur. J. Oral Implantol. 2015, 8, 75-88. [PubMed]

7. Dalago, H.R.; Schuldt Filho, G.; Rodrigues, M.A.; Renvert, S.; Bianchini, M.A. Risk indicators for peri-implantitis. A cross-sectional study with 916 implants. Clin. Oral Implant Res. 2017, 28, 144-150. [CrossRef] [PubMed]

8. Monje, A.; Wang, H.L.; Nart, J. Association of preventive maintenance therapy compliance and peri-implant diseases: A cross-sectional study. J. Periodontol. 2017, 88, 1030-1041. [CrossRef] [PubMed]

9. Rokn, A.; Aslroosta, H.; Akbari, S.; Najafi, H.; Zayeri, F.; Hashemi, K. Prevalence of peri-implantitis in patients not participating in well-designed supportive periodontal treatments: A cross-sectional study. Clin. Oral Implant Res. 2017, 28, 314-319. [CrossRef] [PubMed]

10. Schwarz, F.; Becker, K.; Sahm, N.; Horstkemper, T.; Rousi, K.; Becker, J. The prevalence of peri-implant diseases for two-piece implants with an internal tube-in-tube connection: A cross-sectional analysis of 512 implants. Clin. Oral Implant Res. 2017, 28, 24-28. [CrossRef] [PubMed]

11. Buser, D.; Chappuis, V.; Kuchler, U.; Bornstein, M.M.; Wittneben, J.G.; Buser, R.; Cavusoglu, Y.; Belser, U.C. Long-term stability of early implant placement with contour augmentation. J. Dent. Res. 2013, 92, 176S-182S. [CrossRef] [PubMed]

12. Jung, R.E.; Benic, G.I.; Scherrer, D.; Hammerle, C.H. Cone beam computed tomography evaluation of regenerated buccal bone 5 years after simultaneous implant placement and guided bone regeneration procedures-A randomized, controlled clinical trial. Clin. Oral Implant Res. 2015, 26, 28-34. [CrossRef] [PubMed]

13. Elnayef, B.; Monje, A.; Gargallo-Albiol, J.; Galindo-Moreno, P.; Wang, H.L.; Hernández-Alfaro, F. Vertical ridge augmentation in the atrophic mandible: A systematic review and meta-analysis. Int. J. Oral Maxillofac. Implant 2017, 32, 291-312. [CrossRef]

14. Chappuis, V.; Cavusoglu, Y.; Buser, D.; von Arx, T. Lateral ridge augmentation using autogenous block grafts and guided bone regeneration: A 10-year prospective case series study. Clin. Implant Dent. Relat. Res. 2017, 19, 85-96. [CrossRef] [PubMed]

15. Urban, I.A.; Monje, A.; Nevins, M.; Nevins, M.L.; Lozada, J.; Wang, H.L. Surgical management of significant maxillary anterior vertical ridge defects. Int. J. Periodont. Restor. Dent. 2016, 36, 329-337. [CrossRef] [PubMed]

16. Tran, D.T.; Gay, I.C.; Diaz-Rodriguez, J.; Parthasarathy, K.; Weltman, R.; Friedman, L. Survival of dental implants placed in grafted and nongrafted bone: A retrospective study in a university setting. Int. J. Oral Maxillofac. Implant 2016, 31, 310-317. [CrossRef] [PubMed]

17. Visser, A.; Stellingsma, C.; Raghoebar, G.M.; Meijer, H.J.; Vissink, A. A 15-year comparative prospective study of surgical and prosthetic care and aftercare of overdenture treatment in the atrophied mandible: Augmentation versus nonaugmentation. Clin. Implant Dent. Relat. Res. 2016, 18, 1218-1226. [CrossRef] [PubMed]

18. Ramanauskaite, A.; Borges, T.; Almeida, B.L.; Correia, A. Dental Implant Outcomes in Grafted Sockets: A Systematic Review and Meta-Analysis. J. Oral Maxillofac. Res. 2019, 10. [CrossRef] [PubMed]

19. Carcuac, O.; Abrahamsson, I.; Derks, J.; Petzold, M.; Berglundh, T. Spontaneous progression of experimental peri-implantitis in augmented and pristine bone: A pre-clinical in vivo study. Clin. Oral Implant Res. 2020, 31, 192-200. [CrossRef] [PubMed]

20. Jemt, T. Implant Survival in the Edentulous Jaw-30 Years of Experience. Part I: A Retro-Prospective Multivariate Regression Analysis of Overall Implant Failure in 4,585 Consecutively Treated Arches. Int. J. Prosthodont. 2018, 31, 425-435. [CrossRef] [PubMed]

21. Pontoriero, R.; Tonelli, M.P.; Carnevale, G.; Mombelli, A.; Nyman, S.R.; Lang, N.P. Experimentally induced peri-implant mucositis. A clinical study in humans. Clin. Oral Implant Res. 1994, 254-259. [CrossRef] [PubMed]

22. Zitzmann, N.U.; Berglundh, T.; Marinello, C.P.; Lindhe, J. Experimental peri-implant mucositis in man. J. Clin. Periodontol. 2001, 28, 517-523. [CrossRef] [PubMed]

23. Salvi, G.E.; Aglietta, M.; Eick, S.; Sculean, A.; Lang, N.P.; Ramseier, C.A. Reversibility of experimental peri-implant mucositis compared with experimental gingivitis in humans. Clin. Oral Implant Res. 2012, 23, 182-190. [CrossRef] [PubMed]

24. Renvert, S.; Lindahl, C.; Persson, G.R. Occurrence of cases with peri-implant mucositis or peri-implantitis in a 21-26 years follow-up study. J. Clin. Periodontol. 2018, 45, 233-240. [CrossRef] [PubMed] 
25. Zetterqvist, L.; Feldman, S.; Rotter, B.; Vincenzi, G.; Wennstrom, J.L.; Chierico, A.; Kenealy, J.N. A prospective, multicenter, randomized-controlled 5-year study of hybrid and fully etched implants for the incidence of peri-implantitis. J. Periodontol. 2010, 81, 493-501. [CrossRef]

26. Koldsland, O.C.; Scheie, A.A.; Aass, A.M. Prevalence of peri-implantitis related to severity of the disease with different degrees of bone loss. J. Periodontol. 2010, 81, 231-238. [CrossRef] [PubMed]

27. Sanz, M.; Chapple, I.L.; Working Group 4 of the VIII European Workshop on Periodontology. Clinical research on peri-implant diseases: Consensus report of Working Group 4. J. Clin. Periodontol. 2012, 39, 202-206. [CrossRef]

28. Leblebicioglu, B.; Hegde, R.; Yildiz, V.O.; Tatakis, D.N. Immediate effects of tooth extraction on ridge integrity and dimensions. Clin. Oral Investig. 2015, 19, 1777-1784. [CrossRef] [PubMed]

29. Salvi, G.E.; Monje, A.; Tomasi, C. Long-term biological complications of dental implants placed either in pristine or in augmented sites: A systematic review and meta-analysis. Clin. Oral Implant Res. 2018, 29, 294-310. [CrossRef] [PubMed]

30. Roccuzzo, M.; Bonino, L.; Dalmasso, P.; Aglietta, M. Long-term results of a three arms prospective cohort study on implants in periodontally compromised patients: 10-year data around sandblasted and acid-etched (SLA) surface. Clin. Oral Implant Res. 2014, 25, 1105-1112. [CrossRef] [PubMed]

31. Tenenbaum, H.; Bogen, O.; Séverac, F.; Elkaim, R.; Davideau, J.L.; Huck, O. Long-term prospective cohort study on dental implants: Clinical and microbiological parameters. Clin. Oral Implant Res. 2017, 28, 86-94. [CrossRef]

32. Roccuzzo, A.; De Ry, S.; Sculean, A.; Roccuzzo, M.; Salvi, G.E. Current approaches for the non-surgical management of periimplant diseases. Curr. Oral Health Rep. 2020. [CrossRef]

33. De Ry, S.P.; Roccuzzo, A.; Sculean, A.; Salvi, G.E. Nichtchirurgische Therapie periimplantärer Erkrankungen. Implantologie 2020, 28, 117-127.

34. Schwarz, F.; Schmucker, A.; Becker, J. Efficacy of alternative or adjunctive measures to conventional treatment of peri-implant mucositis and peri-implantitis: A systematic review and meta-analysis. Int. J. Implant. Dent. 2015, 22. [CrossRef] [PubMed]

35. Heitz-Mayfield, L.J.A.; Salvi, G.E.; Mombelli, A.; Loup, P.J.; Heitz, F.; Kruger, E.; Lang, N.P. Supportive peri-implant therapy following anti-infective surgical peri-implantitis treatment: 5-year survival and success. Clin. Oral Implant Res. 2018, 29, 1-6. [CrossRef] [PubMed]

36. Roccuzzo, M.; Layton, D.M.; Roccuzzo, A.; Heitz-Mayfield, L.J. Clinical outcomes of peri-implantitis treatment and supportive care: A systematic review. Clin. Oral Implant Res. 2018, 29, 331-350. [CrossRef]

37. Carcuac, O.; Derks, J.; Abrahamsson, I.; Wennström, J.L.; Berglundh, T. Risk for recurrence of disease following surgical therapy of peri-implantitis-A prospective longitudinal study. Clin. Oral Implant Res. 2020, 31, 1072-1077. [CrossRef] [PubMed]

38. Berglundh, T.; Wennström, J.L.; Lindhe, J. Long-term outcome of surgical treatment of peri-implantitis. A 2-11-year retrospective study. Clin. Oral Implant Res. 2018, 29, 404-410. [CrossRef] [PubMed]

39. Roccuzzo, M.; Pittoni, D.; Roccuzzo, A.; Charrier, L.; Dalmasso, P. Surgical treatment of peri-implantitis intrabony lesions by means of deproteinized bovine bone mineral with 10\% collagen: 7-year-results. Clin. Oral Implant Res. 2017, 28, 1577-1583. [CrossRef] [PubMed]

40. Roccuzzo, M.; Fierravanti, L.; Pittoni, D.; Dalmasso, P.; Roccuzzo, A. Implant survival after surgical treatment of peri-implantitis lesions by means of deproteinized bovine bone mineral with $10 \%$ collagen: 10 -year results from a prospective study. Clin. Oral Implant Res. 2020, 31, 768-776. [CrossRef]

41. Parma-Benfenati, S.; Tinti, C.; Romano, F.; Roncati, M.; Aimetti, M. Long-Term Outcome of Surgical Regenerative Treatment of Peri-implantitis: A 2- to 21-Year Retrospective Evaluation. Int. J. Periodont. Restor. Dent. 2020, 40, 487-496. [CrossRef]

42. Romeo, E.; Lops, D.; Chiapasco, M.; Ghisolfi, M.; Vogel, G. Therapy of peri-implantitis with resective surgery. A 3-year clinical trial on rough screw-shaped oral implants. Part II: Radiographic outcome. Clin. Oral Implant Res. 2007, 18, 179-187. [CrossRef] [PubMed]

43. Bianchini, M.A.; Galarraga-Vinueza, M.E.; Apaza-Bedoya, K.; De Souza, J.M.; Magini, R.; Schwarz, F. Two to six-year disease resolution and marginal bone stability rates of a modified resective-implantoplasty therapy in 32 peri-implantitis cases. Clin. Implant Dent. Relat. Res. 2019, 21, 758-765. [CrossRef] [PubMed]

44. Lasserre, J.F.; Brecx, M.C.; Toma, S. Implantoplasty Versus Glycine Air Abrasion for the Surgical Treatment of Peri-implantitis: A Randomized Clinical Trial. Int. J. Oral Maxillofac. Implant 2020, 35, 197-206. [CrossRef] [PubMed]

45. Stavropoulos, A.; Bertl, K.; Eren, S.; Gotfredsen, K. Mechanical and biological complications after implantoplasty-A systematic review. Clin. Oral Implant Res. 2019, 30, 833-848. [CrossRef] [PubMed]

46. Persson, L.G.; Berglundh, T.; Lindhe, J.; Sennerby, L. Re-osseointegration after treatment of peri-implantitis at different implant surfaces. An experimental study in the dog. Clin. Oral Implant Res. 2001, 12, 595-603. [CrossRef] [PubMed]

47. Fletcher, P.; Deluiz, D.; Tinoco, E.M.; Ricci, J.L.; Tarnow, D.P.; Tinoco, J.M. Human Histologic Evidence of Reosseointegration Around an Implant Affected with Peri- implantitis Following Decontamination with Sterile Saline and Antiseptics: A Case History Report. Int. J. Periodont. Restor. Dent. 2017, 37, 499-508. [CrossRef] [PubMed]

48. Behneke, A.; Behneke, N.; d'Hoedt, B. Treatment of peri-implantitis defects with autogenous bone grafts: Six-month to 3-year results of a prospective study in 17 patients. Int. J. Oral Maxillofac. Implant 2000, 15, 125-138.

49. Khoury, F.; Buchmann, R. Surgical therapy of peri-implant disease: A 3-year follow-up study of cases treated with 3 different techniques of bone regeneration. J. Periodontol. 2001, 72, 1498-1508. [CrossRef] [PubMed] 
50. Roos-Jansåker, A.M.; Renvert, H.; Lindahl, C.; Renvert, S. Surgical treatment of peri-implantitis using a bone substitute with or without a resorbable membrane: A prospective cohort study. J. Clin. Periodontol. 2007, 34, 625-632. [CrossRef] [PubMed]

51. Schwarz, F.; Sculean, A.; Bieling, K.; Ferrari, D.; Rothamel, D.; Becker, J. Two-year clinical results following treatment of periimplantitis lesions using a nanocrystalline hydroxyapatite or a natural bone mineral in combination with a collagen membrane. $J$. Clin. Periodontol. 2008, 35, 80-87. [CrossRef] [PubMed]

52. Schwarz, F.; Sahm, N.; Schwarz, K.; Becker, J. Impact of defect configuration on the clinical outcome following surgical regenerative therapy of peri-implantitis. J. Clin. Periodontol. 2010, 37, 449-455. [CrossRef] [PubMed]

53. Roccuzzo, M.; Bonino, F.; Bonino, L.; Dalmasso, P. Surgical therapy of peri-implantitis lesions by means of a bovine-derived xenograft: Comparative results of a prospective study on two different implant surfaces. J. Clin. Periodontol. 2011, 28, 738-745. [CrossRef] [PubMed]

54. Aghazadeh, A.; Persson, R.G.; Renvert, S. A single-centre randomized controlled clinical trial on the adjunct treatment of intra-bony defects with autogenous bone or a xenograft: Results after 12 months. J. Clin. Periodontol. 2012, 39, 666-673. [CrossRef] [PubMed]

55. Roccuzzo, M.; Gaudioso, L.; Lungo, M.; Dalmasso, P. Surgical therapy of single peri-implantitis intrabony defects, by means of deproteinized bovine bone mineral with 10\% collagen. J. Clin. Periodontol. 2016, 43, 311-318. [CrossRef] [PubMed]

56. Renvert, S.; Roos-Jansaker, A.M.; Persson, G.R. Surgical treatment of peri-implantitis lesions with or without the use of a bone substitute-a randomized clinical trial. J. Clin. Periodontol. 2018, 45, 1266-1274. [CrossRef] [PubMed]

57. Tomasi, C.; Regidor, E.; Ortiz-Vigón, A.; Derks, J. Efficacy of reconstructive surgical therapy at peri-implantitis-related bone defects. A systematic review and meta-analysis. J. Clin. Periodontol. 2019, 46, 340-356. [CrossRef] [PubMed]

58. Isehed, C.; Holmlund, A.; Renvert, S.; Svenson, B.; Johansson, I.; Lundberg, P. Effectiveness of enamel matrix derivative on the clinical and microbiological outcomes following surgical regenerative treatment of peri-implantitis. A randomized controlled trial. J. Clin. Periodontol. 2016, 43, 863-873. [CrossRef]

59. Wohlfahrt, J.C.; Lyngstadaas, S.P.; Rønold, H.J.; Saxegaard, E.; Ellingsen, J.E.; Karlsson, S.; Aass, A.M. Porous titanium granules in the surgical treatment of peri-implant osseous defects: A randomized clinical trial. Int. J. Oral Maxillofac. Implant 2012, 27, 401-410.

60. Jepsen, K.; Jepsen, S.; Laine, M.L.; Anssari Moin, D.; Pilloni, A.; Zeza, B.; Sanz, M.; Ortiz-Vigon, A.; Roos-Jansåker, A.M.; Renvert, S. Reconstruction of Peri-implant Osseous Defects: A Multicenter Randomized Trial. J. Dent. Res. 2016, 95, 58-66. [CrossRef]

61. Matarasso, S.; Iorio Siciliano, V.; Aglietta, M.; Andreuccetti, G.; Salvi, G.E. Clinical and radiographic outcomes of a combined resective and regenerative approach in the treatment of peri-implantitis: A prospective case series. Clin. Oral Implant Res. 2014, 25, 761-767. [CrossRef] [PubMed]

62. Schwarz, F.; John, G.; Schmucker, A.; Sahm, N.; Becker, J. Combined surgical therapy of advanced peri-implantitis evaluating two methods of surface decontamination: A 7-year follow-up observation. J. Clin. Periodontol. 2017, 44, 337-342. [CrossRef] [PubMed]

63. Monje, A.; Pons, R.; Roccuzzo, A.; Salvi, G.E.; Nart, J. Reconstructive therapy for the management of peri-implantitis via submerged guided bone regeneration: A prospective case series. Clincal Implant. Dent. Relat. Res. 2020, 22, 342-350. [CrossRef] [PubMed]

64. Roccuzzo, M.; Dalmasso, P.; Pittoni, D.; Roccuzzo, A. Treatment of buccal soft tissue dehiscence around single implant: 5-year results from a prospective study. Clin. Oral Investig. 2019, 23, 1977-1983. [CrossRef] [PubMed]

65. Monje, A.; Blasi, G. Significance of keratinized mucosa/gingiva on peri-implant and adjacent periodontal conditions in erratic maintenance compliers. J. Periodontol. 2019, 5, 445-453. [CrossRef] [PubMed]

66. Roccuzzo, M.; Grasso, G.; Dalmasso, P. Keratinized mucosa around implants in partially edentulous posterior mandible: 10-year results of a prospective comparative study. Clin. Oral. Implant. Res. 2016, 4, 491-496. [CrossRef] [PubMed]

67. Ravidà, A.; Saleh, I.; Siqueira, R.; Garaicoa-Pazmiño, C.; Saleh, M.H.A.; Monje, A.; Wang, H.L. Influence of keratinized mucosa on the surgical therapeutical outcomes of peri-implantitis. J. Clin. Periodontol. 2020, 4, 529-539. [CrossRef] [PubMed]

68. Monje, A.; Blasi, G.; Nart, J.; Urban, I.A.; Nevins, M.; Wang, H.L. Soft Tissue Conditioning for the Surgical Therapy of Periimplantitis: A Prospective 12-Month Study. Int. J. Periodont. Restor. Dent. 2020, 6, 899-906. [CrossRef] [PubMed] 